\title{
The sustainable development and application of indoor environmental protection materials
}

\author{
Xiaodong Zhang ${ }^{1, a}$, Changrong Peng ${ }^{2, b}$ \\ ${ }^{1}$ Environmental Art Design, Hebei Institute of Fine Arts,XinLe,ShiJiaZhuang,050700,China. \\ ${ }^{2}$ Animation school, Hebei Institute of Fine Arts,XinLe,ShiJiaZhuang,050700,China. \\ a53404618@qq.com, ${ }^{b} 274979545 @ q q . c o m$
}

Keywords: Environmental protection, Energy saving, Hazardous substances

\begin{abstract}
Material mode of existence, inevitably determines its color, texture, feel, and other physical properties and chemical properties, a good designer should also be a fantastic material user. He can produce emotional communicate with material, will put the material in one of the most appropriate location. Interior decoration design is to express the visual space transformation through the simple sense of decoration materials selection and comprehensive application by designer. Interior design is not only the space level, more important is the performance of the material surface texture, the visual and tactile sensations, and application in the design of material should be healthy, environmental protection.
\end{abstract}

\section{Section One: The basic principles of selection of material}

Various impressive appeal created by designers' optical applications about material form, light, texture, is the use of these materials, design to implementation. Color and texture to the material surface determines the atmosphere of the space. The choice of appropriate materials is crucial in the design, and is inseparable with design concepts. The ideas of the designer can be strengthened or weakened due to the use of a specific material. When the material is consciously used in the new form, special way of application, new experience and the tension is created. for example, Wandel Hoefer Lorch work out the industrialized manufacturing of brass fabric ,among the design of the altar of Dresden Jewish, O M A firm design Porto Casa da Musica metope plywood golden leaf ornamental in the music, etc. According to the different texture of the decorative materials with different design, the interior space effect, aesthetic feeling form is different, in limited living environment extend the space feeling. Also, the designer can make good use of the furniture material, equipment, to reasonable divide the interior space be proper arrangement, and this will create more space levels, more style, make interior space is able to effectively use . There are many different kinds of decorative materials, and various forms, we must analyze these materials, synthesis, induction, do reasonable selection and application of materials, expressive and exert its performance and space aesthetic feeling. Not only make material has a sense of harmony and comfort, but also the visual aesthetic feeling of the space.

Reasonable use different material :The requirement of choose material should meet people's visual feel first. Such as our bedroom needs in a comfortable and healthy environment, surrounded by soft material. in order to meet the needs of the people sleeping environment. Design should experience the needs of users itself.

Visual feel of material :Visual aesthetic feeling about space material, is a compulsory course for designers. The visual three elements of decoration materials contain surface color, quality, skin texture, these give the material medium to designer how to use the material to performance. not only to know what the material of understanding for monomer, and to realize the combination of different materials and the contrast relationship. What's more to grasp and ascend from the understanding of the concrete to the abstract aesthetic cognition. Intuitive observation and judgment sensitivity to material is the most basic quality of the designers, the purpose is to reach combination unity to different decoration material. For choice and the use of decorative materials are usually based on the three basic elements: 
(1) Color tone. When applying color adornment, different indoor environment is often subject to the environment space use function, the influence of different tone, color can cause people to different physiological and psychological feeling, only by using the appropriate color and tone, can make the design of environmental space decoration to achieve the perfect unity of practicality and artistry. So first of all, decoration materials, furniture, adorn article itself has its inherent color: second, structure characteristics of adornment material will also affect the adornment color ,high density material will be relatively brighter color, low density material will be a little dark. So objects combination is very important in material selection and application of color. Choice the color of decoration materials material itself, must be combined with the internal space design, the light source, the formation of different color combination, this is the reasonable use and application of material color. At the same time also should to consider collocation relationship between bulk adornment material color: different color contrast, similar color contrast, brightness, contrast.

(2) Quality of a material. Quality is the surface characteristic on material. Such as metal hard texture, rough texture of brick, soft and smooth texture of glass, etc. As a designer, we must give full consideration to the relationship between the two in the process of interior design. Pure interior design for performance visual feel, can consider more visual contrast, expressions and tension, the distribution of the material texture scale, proportion to the size and other factors. Quality of a material is through the tactile and visual perception experience by person. Some material has affinity with their relationship, as well as visual aesthetic feeling.

(3) Texture. Texture is the veins and lines of the material surface. Material surface texture is very rich and colorful. Trees have different skin texture by different species, stone material is the same. Seek different texture change is the important manifestation of decoration materials in the process of interior design material, In view of the material texture itself, sometimes it will be to the design of interior designers to play an important guiding role, greatly enriched the expressive force of interior space. To be emphasized is that it is inseparable about the application of materials and physics of light and shadow. Interior decoration materials is not isolated, it is in a unified under the condition of space environment. Light plays a very important role by the display space of material and skin texture beauty. Our designers will have certain design theme, the show for the theme is very diverse in form. Designer should make full consideration about the comprehensive thinking and research about features of material texture. The first to be targeted and selectively use professional knowledge and experience what we have studied, look for the possibilities that can reflect the design theme. By selecting the most appropriate texture supported by different various forms ,texture materials ,finally forms the reasonable, accurate, clear expression of the design theme in indoor effect.

\section{Section Two: Harm and measures by inferior decoration material}

Health problems more and more get the attention of people, green and environmental protection as a indicator of health can not be ignored, and is closely related to people's daily life .In order to ensure the modern demands for healthy living, this is absolutely can not be ignored.

Mainly classification of hazardous substances. About $80 \%$ of the time in people's life is spent in indoor, this means that people breathe the air every day most come from the interior. According to the survey of the U.S. environmental protection agency, the indoor air pollution is usually $2 \sim 5$ times than outdoor, in some cases, indoor air pollution is higher than outdoor likely to more than 100 times. Various reasons for indoor air pollution, biological pollution, parasites, pathogens such as pets, all kinds of corruption toadstool, cigarette smoke dust pollution and so on, but in addition the more important reason is that in decoration nowadays, routine use of decoration materials containing formaldehyde, TVOC, radon, ammonia and other toxic elements, such as man-made harmful chemicals board containing (plywood, particle board, joinery board, fiberboard, etc.), wooden furniture, paint, chemical fibber carpet, wallpaper, stone base of adhesives and other decorative materials. According to the harm quality to human body, harmful material can be divided into four categories: irritants substances, allergic substance, carcinogenic substances and reproductive toxicity substances. Of course the above classification is not very strict, because most 
of the harmful effects are not single, but a compound. Many harmful substances such as irritating, smells are not very good, is the body produce allergic reaction, carcinogenic for a long time. In the framework of building materials and decoration materials ,as many as hundreds of volatile organic compounds, it has become primary chemical pollution problems in our country of the residential environment. Diseases caused by decoration materials and induce a lot of cases have been reported, so should cause people to pay special attention. The following focuses on toxicity of formaldehyde material impact on human health.

Formaldehyde. Formaldehyde is a colorless, volatile higher organic resin compound, for high toxic substances, toxic chemicals in our country at the second priority control list. Formaldehyde has been determined to be carcinogenic and deformed material by the world health organization, is recognized as the allergy source. It is used for synthetic adhesives, such as resin, urea formaldehyde resin, etc. There are so many adornment material use formaldehyde such as particle board, man-made board, plywood, joinery board, in the (high) density fiber board, solid mu fu joins floor, aggrandizement is compound the floor and its products, etc., In addition in your wardrobe, wooden furniture, wall, floor, laying of wallpaper, chemical fibber carpet, plastic floor, floor paint with urea formaldehyde resin foam as an insulating material of precast slab, etc., also can release the formaldehyde and other harmful gas. The influence to human body health major reflected on irritating allergy, smell abnormalities, immune dysfunction, abnormal lung function, etc. When the formaldehyde content in indoor air is higher than $0.5 \mathrm{mg} / \mathrm{m} 3$, excitant gas can make our eyes shed tears; $0.6 \mathrm{mg} / \mathrm{m} 3$, can cause throat discomfort or pain; If more higher concentrations can cause the symptom such as vomiting, nausea, chest tightness, cough; Exposure to low concentration formaldehyde smell, also can appear have a headache, dizziness, fatigue, excessive sweating and visual impairment, and can inhibit the secretion of sweat gland, lead to produce strong irritating to respiratory tract, eye and skin, cause serious damage to the nervous system, etc., when up to 30 $\mathrm{mg} / \mathrm{m} 3$, would immediately kill people. The gas is mainly derived from artificial board, density board, wood furniture, paint, adhesives, paint, wallpaper, wall cloth, 107 glue, etc.

Low carbon, energy saving, environmental protection concept. With the continuous development of modern society, people pay more and more attention to the living environment, low carbon, energy saving, environmental protection concept gradually into people's minds. The resources are limited on earth, deforestation, waste of non-renewable resources, the climate warming, disasters, frequently occur. Earth people should wake up, low carbon life reflects our worries about the future because of climate change. The global temperature rising. This year China's southwest drought, floods in many southern provinces that we humans have to attach importance to the current problems such as the ecological environment. We gradually realize that industrial production and excessive consumption of excessive carbon emissions is one of the important cause of global warming, therefore we need to control certain consumption and production activities to reduce carbon emissions, practice a low carbon life.

Because the non-renewable resources is limited, such as oil, coal, etc., people to save energy, have to start from the subtleties, starts from the minor matter, more use of renewable resources. Our decorative material enterprise should develop more complex products of alternative products, such as polymer composite decorative board can replace real wood plank, also can copy marble products, has reached to save energy resources and meet the interior decoration effect, environmental protection and is beneficial to people healthy.

"Environmental protection" is an international concept, ISO14001 international environmental system standards has been recognized around the world, become the common rule of environmental protection. It includes four aspects: 1 , the source of raw materials must be protect, not damage the environment, resources can be recycled; 2, the production process must be environmentally friendly, not cause environmental pollution and destruction; 3, the product must be environmental protection, be healthy, safe, cause no harm to human body; 4 , the use of products should be environmentally friendly, waste will not cause pollution and destruction to the environment.

In modern society, the mass production and utility of building materials, ignoring the basic decoration materials of environmental protection is one of the main cause of pollution. So, to 
protect our survival environment, realize the sustainable development of architectural environment design. You must put the environmental impact made by using of non-renewable resources and inferior product into measure the value of building decoration environment monitoring system. The good construction environment is take from the natural and return to natural, it's sustainable creative engineering. , building decoration materials should be used by the environmental protection, should not do harm to human body and the surrounding environment. We firmly believe that developing and promoting environmental protection adornment material, use modern high-tech means to carry on the design, will be able to realize the sustainable development of residential environment gradually become a reality. In this way can we create a very practical, comfortable, healthy room in the space environment, make people obtain spiritual satisfaction and enjoy of beauty, so as to improve people's quality of life.

\section{Reference}

[1] The Rural Residential Technology Based on Renewable Energy System Design Research, Liu Wenhe, China Building Industry Press, 2014-5-1 1

[2]Evaluation Standard about Renewable energy Construction Application Engineering (GB/T50801-2013), National Standards of the People's Republic of China

[3] Water structure and the sustainable development, Wang Qiaoling, World book publishing company, 2014-4-1

[4] For the sustainable development of resources city ecological environment evaluation, Xia Qing, science press, 2010-1-1

[5] The problem of water resources and the sustainable development strategy research in China, wang hao, China electric power press, 2010-4-1

[6] Resources city sustainable development research, Li Jianhua, social sciences academic press, 2007-5-1

[7] Marine resources and the sustainable development in China, liang-min huang, science press, 2007-2-1

[8] Resource depletion region economic transformation and sustainable development research, ji-jun tang, economic science press, 2012-3-1 